\title{
Fibromyalgia: heterogeneity in personality and psychopathology and its implications
}

\author{
Bárbara Gonzalez, Rosa Novo \& Ana Sousa Ferreira
}

To cite this article: Bárbara Gonzalez, Rosa Novo \& Ana Sousa Ferreira (2019): Fibromyalgia: heterogeneity in personality and psychopathology and its implications, Psychology, Health \& Medicine, DOI: 10.1080/13548506.2019.1695866

To link to this article: https://doi.org/10.1080/13548506.2019.1695866

曲 Published online: 24 Nov 2019.

Submit your article to this journal $\pi$

Џ Article views: 2

Q View related articles $₫$

View Crossmark data $\asymp$ 


\title{
Fibromyalgia: heterogeneity in personality and psychopathology and its implications
}

\author{
Bárbara Gonzalez (iD) ${ }^{a}$, Rosa Novo $\mathbb{( D}^{\mathrm{b}}$ and Ana Sousa Ferreira (iD ${ }^{\mathrm{c}}$ \\ aHEI-Lab: Digital Human-Environment Interactions Lab, Universidade Lusófona de Humanidades \\ e Tecnologias, Lisbon, Portugal; ' ${ }^{b} \mathrm{CICPSI}$ (Research Centre in Psychological Science), Faculdade de Psicologia, \\ Universidade de Lisboa, Alameda da Universidade, Lisbon, Portugal; 'Faculdade de Psicologia, Universidade \\ de Lisboa and Business Research Unit (BRU-IUL), Lisbon, Portugal
}

\begin{abstract}
The fibromyalgia syndrome (FM) is a chronic widespread pain condition whose etiology remains unknown and no treatment has satisfactory levels of success. A meta-analysis has identified a distinct Minnesota Multiphasic Personality Inventory-2 (MMPI-2) clinical profile between FM female patients and healthy controls, and differences between FM and other chronic pain condition with clear etiology have also been found. However, heterogeneity in this population has been suggested in several studies. We aim to assess clinical aspects in FM patients, based on personality psychopathology characteristics, in order to explore heterogeneity and the existence of core common aspects. In this cross-sectional study, a relatively homogeneous sample of 56 female FM patients $\left(M_{\text {age }}\right.$ $=45.95, S D_{\text {age }}=9.39$ ) was assessed through MMPI-2. A K-Means cluster analysis identified two clusters, one $(n=24)$ with clinically significant levels in Negative Emotionality and Introversion scales. Subsequent MANOVAs identified important features of this cluster on several MMPI-2 dimensions. Moreover, several dimensions are clinically elevated in both clusters. In conclusion, the combination of psychopathological negative emotionality, interpersonal isolation, and low hedonic capacity, in a group of patients, has implications for the daily living and treatment of FM patients, and several core aspects of FM need to be addressed.
\end{abstract}

\section{ARTICLE HISTORY}

Received 3 May 2019

Accepted 12 November 2019

\section{KEYWORDS}

Fibromyalgia; personality

characteristics;

psychopathology

dimensions; MMPI-2

Fibromyalgia (FM) is a syndrome characterized by chronic widespread pain, which is frequently associated with fatigue, sleep disorder, other functional somatic syndromes, mental and physical disorders, as well as disability and diminished quality of life. Although a central sensitization phenomena has been associated to FM (Ablin et al., 2012; Arnold et al., 2016) the etiopathology of FM remains unknown (Thieme, Mathys, \& Turk, 2017). Some authors conceptualize this syndrome as part of a group of affective spectrum disorders (e.g., Arnold et al., 2004), as it has a high comorbidity with psychiatric disorders. In addition, a high prevalence of alexithymia has been found in FM patients (Di Tella et al., 2018). The fact that FM is a medically unexplained syndrome, and the quality of evidence of a large range of treatments for FM are only modest and has

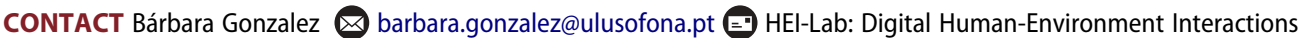
Lab, Universidade Lusófona de Humanidades e Tecnologias, Avenida do Campo Grande, 376, 1749-024, Lisbon, Portugal (c) 2019 Informa UK Limited, trading as Taylor \& Francis Group 
not shown significant improvement over the past two decades (Thieme et al., 2017) presents a challenge to clinical psychology and its contribution to the understanding and treatment of FM.

In the scope of an integrative biopsychosocial approach to FM, psychological aspects may play an important role as predisposing factors to FM, and personality is one of those aspects (Eich, Hartmann, Muller, \& Fischer, 2000; Malin \& Littlejohn, 2012; Van Houdenhove, Luyten, \& Egle, 2009). Within a diathesis-stress model of disease, some personality and psychopathology features that make people more vulnerable to stressors would be antecedent to FM, interacting with physiological vulnerabilities to the development of the syndrome (Thiagarajah, Guymer, Leech, \& Littlejohn, 2014).

A recent meta-analysis focused on the Minnesota Multiphasic Personality Inventory (MMPI-2) has shown that female FM patients have a psychopathology profile significantly different than the profile of healthy volunteers (Novo, Gonzalez, Peres, \& Aguiar, 2017a, 2017b). Nevertheless, it also acknowledged that the FM patients are probably a heterogeneous group regarding personality and psychopathology profiles.

Pertaining to psychopathology, with the original MMPI, Ahles, Yunus, Riley, Bradley, and Masi (1984) found a large group of FM patients with a clinical profile within the normal range, followed by a group with the typical chronic pain profile (clinically significant scores on the 'neurotic triad scales', i.e., hypochondriasis, depression and hysteria), and a smaller group with the psychopathological profile (significant elevations in several clinical scales) was found. On the contrary, some studies found a larger cluster with the psychopathological profile (Claros et al., 2006; Porter-Moffitt et al., 2006).

Pertaining to personality only, within the five factor model of personality, a cluster with higher Neuroticism and lower Conscienciousness is identified (Bucourt et al., 2018; Torres et al., 2013) and also with lower Extraversion (Torres et al., 2013) associated with more self-reported pain (Bucourt et al., 2018).

Finally, the distressed type or Type D personality, a specific combination of Negative Affectivity and Social Inhibition, has been more recently studied in this population, and it constitutes our main interest. Van Middendorp et al. (2016) found a high prevalence within an FM sample, and Ablin, Zohar, Zaraya-Blum, and Buskila (2016) found a higher prevalence of Type D personality in one of the FM clusters, associated with a less adaptive pattern.

In conclusion, we intend to explore heterogeneity based on structural personality psychopathology dimensions (as most of the studies focus on clinical psychopathology dimensions), within a community sample with a homogeneous age range. We hypothesize that different clinical levels in the psychopathology and personality dimensions will be found.

\section{Method}

\section{Participants}

The participants were $56 \mathrm{FM}$ female patients between 30 and 60 years old $(M=45.95$; $S D=9.39$ ). The inclusion criteria were: Having a pure FM diagnosis (not having another rheumatic disease or painful condition) for at least six months. Finally, all the participants had the response consistency levels (VRIN and TRIN validity scales) within the normal range. 


\section{Instruments}

We used MMPI-2 (Butcher, Dahlstrom, Graham, Tellegen, \& Kaemmer, 1989) in a Portuguese version (Silva, Novo, Prazeres, \& Pires, 2006), is a self-administered inventory to assess clinical and personality psychopathology. The results are converted into normalized T-scores, and in general terms, $\mathrm{T}>65$ are clinically significant. In clinical scales, internal consistency coefficients range between .34 and .87 , most of them in .80 .

\section{Procedure}

Most of the FM patients were recruited through a patient's association, contacted by telephone and asked about the inclusion criteria and availability to participate in the study. The remaining FM patients were recruited within the scope of a psychological assessment service in a university centre open to the community. Research with MMPI-2 was approved by the ethic commitee of the North Lisbon Hospital Center. The informed consent was obtained and the privacy was observed in accordance with the principles of the Declaration of Helsinki.

\section{Data analysis}

We conducted K-means non-hierarchical cluster analysis, based on the five MMPI2 personality psychopathology scales (PSY-5: Agressiveness, Psychoticism, Disconstraint, Negative Emotionality/Neuroticism, and Introversion/Low Positive Emotionality) testing a three clusters solution in the first place. As it was not appropriate, we tested a two clusters solution. We used Chi-Square test to identify the differences between the clusters in the sociodemographic nominal and ordinal variables and a one-way analysis of variance (ANOVA) to test the differences in age and diagnosis duration. We used multivariate analysis of variance (MANOVA) to test the differences between the two clusters in the MMPI-2 clinical scales.

\section{Results}

In the K-means two-cluster solution, based on the scores of the PSY-5 MMPI-2 scales, convergence was achieved after three iterations. The distance between final cluster centers was 23.945. The characterization features are presented in Table 1.

The larger cluster $(n=32)$ has no clinically significant elevation, and the other cluster $(n=24)$ has clinically significant elevations $(\mathrm{T} \geq 65)$ in two scales: Negative Emotionality $(M=65.25, S D=9.66 ; t=-3.38 ; p=.001)$ and Introversion $(M=68.38, S D=9.90 ; t$ $=-8.61 ; p=.000$ (Figure 1 ).

The MANOVA showed significant differences between the clusters in the composite of clinical scales (Wilk's $\Lambda=.415 ; F(10,45)=6.344 ; p=.000 ; \eta^{2}$ par $=.585$ ). Both clusters had clinically significant elevations in Hypochondriasis, Depression, Hysteria, and Schizophrenia (Figure 2), and Cluster 2 also had it in Psychasthenia $(M=69.63$, $S D=8.99 ; t=-3.54 ; p=.001)$. 
Table 1. Sociodemographic characteristics of FM participants.

\begin{tabular}{|c|c|c|c|c|c|c|}
\hline & \multicolumn{2}{|c|}{ Cluster 1} & \multicolumn{2}{|c|}{ Cluster 2} & \multirow[b]{2}{*}{$F$} & \multirow[b]{2}{*}{$p$} \\
\hline & $M$ & $S D$ & $M$ & $S D$ & & \\
\hline Age & 44.38 & 9.34 & 48.04 & 9.22 & 2.14 & .250 \\
\hline \multirow[t]{2}{*}{ Dignosis Duration } & 4.98 & 2.56 & 5.78 & 3.66 & .896 & .348 \\
\hline & $N$ & $\%$ & $N$ & $\%$ & $x^{2}$ & $p$ \\
\hline Marital Status & & & & & 2.21 & .331 \\
\hline Single & 5 & 15.6 & 2 & 8.3 & & \\
\hline Married/cohabiting & 21 & 65.6 & 20 & 83,3 & & \\
\hline Divorced/separated & 6 & 18.8 & 2 & 8.3 & & \\
\hline \multicolumn{7}{|l|}{ Educational level } \\
\hline $1^{\text {st }}$ cycle & 0 & 0 & 2 & 8.3 & 5.65 & .464 \\
\hline $2^{\text {nd }}$ cycle & 2 & 6.3 & 2 & 8.3 & & \\
\hline $3^{\text {rd }}$ cycle & 3 & 9.4 & 4 & 16.7 & & \\
\hline Secondary & 12 & 37.5 & 7 & 29.2 & & \\
\hline Bachelor & 1 & 3.1 & 2 & 8.3 & & \\
\hline University graduation & 12 & 37.5 & 5 & 20.8 & & \\
\hline Master & 2 & 6.3 & 2 & 8.3 & & \\
\hline Occupational status & & & & & 2.34 & .505 \\
\hline Working & 22 & 68.8 & 15 & 62.5 & & \\
\hline Unemployed & 4 & 12.5 & 1 & 4.2 & & \\
\hline Retired & 4 & 12.5 & 5 & 20.8 & & \\
\hline Other & 2 & 6.3 & 3 & 12.5 & & \\
\hline
\end{tabular}

Note. Cluster $1(n=32)$; Cluster $2(n=24)$.

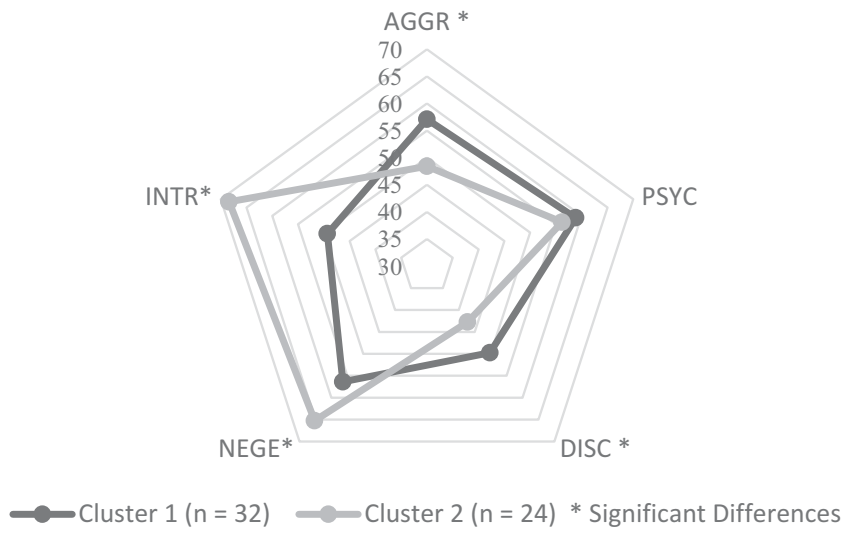

Figure 1. Personality Psychopathology Five Scales (PSY-5) profiles for clusters 1 and 2.

Note. $\mathrm{AGGR}=$ Agressiveness; $\mathrm{PSYC}=$ Psychoticism; $\mathrm{DISC}=$ Disconstraint $; \mathrm{NEGE}=$ Negative Emotionality $/$ Neuroticism; INTR = Introversion/Low Positive Emotionality.

\section{Discussion}

As hipothesized, we found different clinical levels in the psychopathology and personality dimensions of FM patients, organized in two clusters. One of them (cluster 2) is in line with Type D personality found by Ablin et al. (2016), and it is relevant that this cluster has higher Introversion mean levels than the Neuroticism ones. As the presence of positive affect protects against the experiencing of negative affect in times of stress and pain (Davis, Zautra, \& Smith, 2004), this protective aspect is absent in this cluster. As Vendrig, Derksen, and Mey (2000) found that pretreatment higher scores in Introversion predicted decreased satisfaction with the treatment, decreased self-perceived emotional 


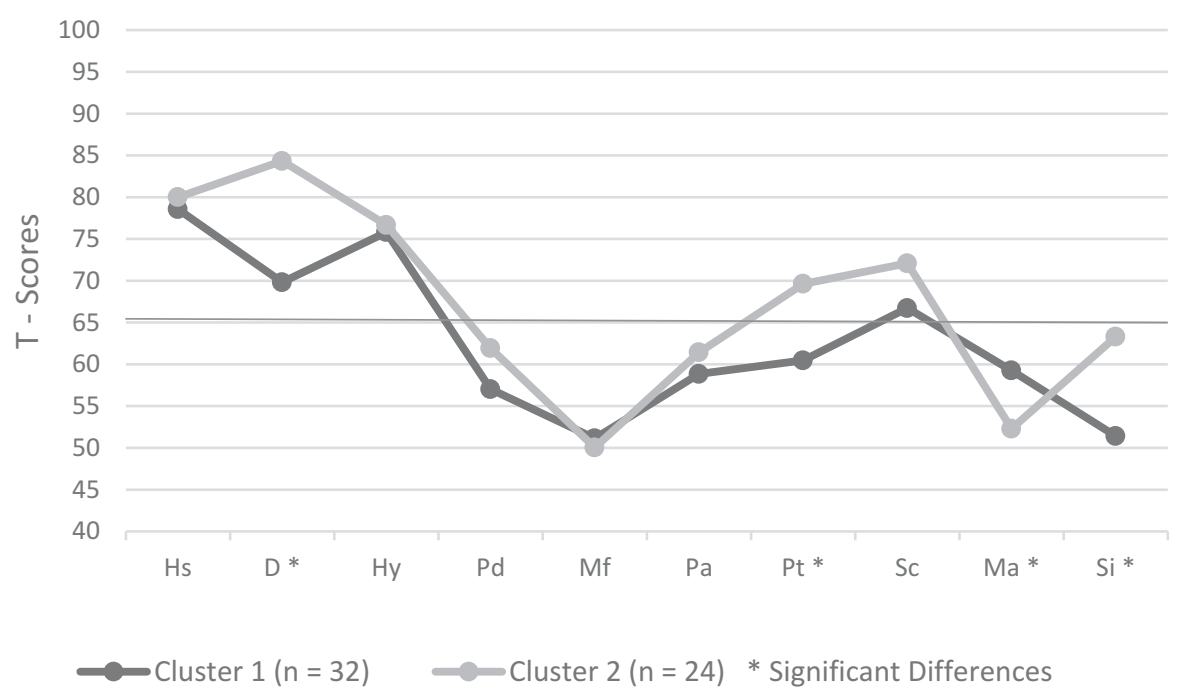

Figure 2. MMPI-2 clinical profiles for clusters 1 and 2.

Note. $\mathrm{Hs}=$ Hypochondriasis; $\mathrm{D}=$ Depression; $\mathrm{Hy}=$ Hysteria; $\mathrm{Pd}=$ Psychopathic Deviate; $\mathrm{Mf}=$ Masculinity/Femininity; $\mathrm{Pa}=$ Paranoia; $\mathrm{Pt}=$ Psychasthenia; $\mathrm{Sc}=$ Schizophrenia; $\mathrm{Ma}=$ Hypomania; $\mathrm{Si}=$ Social Introversion.

change, and a probability of investing less energy in the treatment process, this could be a relevant implication to any intervention with these patients.

Cluster 2 has an extremely high mean level of Depression, as the most elevated scale of the neurotic triad, a configuration that does not characterize chronic pain patients in general, as Hypochondriasis and Hysteria are usually the more elevated scales in these patients (Ahles et al., 1984; Claros et al., 2006; Keller \& Butcher, 1991; Porter-Moffitt et al., 2006). Cluster 2 has also clinically significant levels of Psychasthenia, which corresponds to a diagnosis close to Obsessive-Compulsive Disorder (Graham, 2012).

Apart from heterogeneity, we identified common features of the FM patients. Both clusters have clinically significant levels in the neurotic triad, and in Schizophrenia, reflecting a pathological clinical profile, predominantly neurotic but also reflecting social alienation, unusual beliefs, confusion and lack of adequacy, wich differentiates FM from other chronic pain samples, in which the neurotic triad only is expected to be elevated (e.g., Keller \& Butcher, 1991).

A group of FM patients have relevant personality, clinical and specific features that undoubtedly may compromise any regular chronic pain treatment. This personality pattern has a double implication, at both emotional and relational level, as high Negative Emotionality hinders relations with others, and high Introversion leads to emotional and social disengagement (Friedman, Lewak, Nichols, \& Webb, 2001). Beyond heterogeneity, affective distress is a common aspect to the sample and it should require psychological intervention as part of any medical intervention.

This work has some limitations, mainly the sample dimension, and the absence of a control group. The fact that the sample is composed by women only makes the interpretations appropriate to female fibromyalgia patients only. As strengths of the study, we aimed for a FM community sample, with a homogeneous age range and, to our best knowledge, it is also the first study exploring the heterogeneity in the clinical and 
psychopathological symptomatology in FM patients, based exclusively on structural and relatively stable personality characteristics.

In future research it would be important to study the adherence of FM patients to medical and psychological interventions, the treatment results, and relate them to the personality and psychopathology features.

\section{Disclosure statement}

No potential conflict of interest was reported by the authors.

\section{ORCID}

Bárbara Gonzalez (D) http://orcid.org/0000-0001-5142-256X

Rosa Novo (D) http://orcid.org/0000-0002-4670-6987

Ana Sousa Ferreira (ID) http://orcid.org/0000-0002-3582-4179

\section{References}

Ablin, J. N., Buskila, D., Van Houdenhove, B., Luyten, P., Atzeni, F., \& Sarzi-Puttini, P. (2012). Is fibromyalgia a discrete entity? Autoimmunity Reviews, 11, 585-588.

Ablin, J. N., Zohar, A. H., Zaraya-Blum, R., \& Buskila, D. (2016). Distinctive personality profiles of fibromyalgia and chronic fatigue syndrome patients. PeerJ, 4, e2421.

Ahles, T. A., Yunus, M. B., Riley, S. D., Bradley, J. M., \& Masi, A. T. (1984). Psychological factors associated with primary fibromyalgia syndrome. Arthritis \& Rheumatism, 27, 1101-1106.

Arnold, L. M., Choy, E., Clauw, D. J., Goldenberg, D. L., Harris, R. E., Helfenstein, M., Jr, \& Wang, G. (2016). Fibromyalgia and chronic pain syndromes: A white paper detailing current challenges in the field. Clinical Journal of Pain, 32, 737-746.

Arnold, L. M., Hudson, J. I., Hess, E. V., Ware, A. E., Fritz, D. A., Auchenbach, M. B., ... Keck, P. E., Jr. (2004). Family study of fibromyalgia. Arthritis \& Rheumatism, 50, 944-952.

Bucourt, E., Martaillé, V., Mulleman, D., Goupille, P., Joncker-Vannier, I., Huttenberger, B., ... Courtois, R. (2018). Comparaison des cinq grands traits de personnalité dans la fibromyalgie et les autres maladies rhumatismales. Revue Du Rheumatisme, 85, 188-194.

Butcher, J. N., Dahlstrom, W. G., Graham, J. R., Tellegen, A., \& Kaemmer, B. (1989). The Minnesota Multiphasic Personality Inventory-2 (MMPI-2): Manual for administration and scoring. Minneapolis: University of Minnesota Press.

Claros, L., Cano, M., Presa, A., Barceló, J., Satamán, P., Roca, J., ... Pàmias, M. (2006). Perfiles clínicos en pacientes con fibromialgia que acuden a un centro de salud mental: Obtención de un índice predictivo de gravedad psicopatológica. Actas Españolas De Psiquiatria, 34, 112-122.

Davis, M. C., Zautra, A. J., \& Smith, B. W. (2004). Chronic pain, stress, and the dynamics of affective differentiation. Journal of Personality, 72, 1133-1159.

Di Tella, M., Tesio, V., Ghiggia, A., Romeo, A., Colonna, F., Fusaro, E., ... Castelli, L. (2018). Coping strategies and perceived social support in fibromyalgia syndrome: Relationship with alexithymia. Scandinavian Journal of Psychology, 59, 167-176.

Eich, W., Hartmann, M., Muller, A., \& Fischer, H. (2000). The role of psychosocial factors in fibromyalgia syndrome. Scandinavian Journal of Rheumatology, 29, 30-31.

Friedman, A. F., Lewak, R., Nichols, D. S., \& Webb, J. T. (2001). Psychological assessment with the MMPI-2. Mahwah, NJ: Lawrence Erlbaum Associates.

Graham, J. R. (2012). MMPI-2: Assessing personality and psychopathology (5th ed.). New York, NY: Oxford University Press.

Keller, L. S., \& Butcher, J. N. (1991). Assessment of chronic pain patient with the MMPI-2. Minneapolis: University of Minnesota Press. 
Malin, K., \& Littlejohn, G. O. (2012). Personality and fibromyalgia syndrome. The Open Rheumatology Journal, 6, 273-285.

Novo, R., Gonzalez, B., Peres, R., \& Aguiar, P. (2017a). A meta-analysis of studies with the Minnesota Multiphasic Personality Inventory in fibromyalgia patients. Personality and Individual Differences, 116, 96-108.

Novo, R., Gonzalez, B., Peres, R., \& Aguiar, P. (2017b). Corrigendum to "A meta-analysis of studies with the Minnesota Multiphasic Personality Inventory in fibromyalgia patients". Personality and Individual Differences. doi:10.1016/j.paid.2017.07.022

Porter-Moffitt, S., Gatchel, R. J., Robinson, R. C., Deschner, M., Posamentier, M., Polatin, P., \& Lou, L. (2006). Biopsychosocial profiles of different pain diagnostic groups. The Journal of Pain, 7, 308-318.

Silva, D., Novo, R., Prazeres, N., \& Pires, R. (2006). Inventário Multifásico de Personalidade de Minnesota (Adultos): Versão experimental portuguesa do MMPI-2 [Minnesota Multiphasic Personality Inventory (Adults): Portuguese experimental version of MMPI-2]. Lisboa: Centro de Investigação em Psicologia e Faculdade de Psicologia da Universidade de Lisboa.

Thiagarajah, A. S., Guymer, E. K., Leech, M., \& Littlejohn, G. O. (2014). The relationship between fibromyalgia, stress and depression: Why does stress lead to fibromyalgia in some patients? International Journal of Clinical Rheumatology, 9, 371-384.

Thieme, K., Mathys, M., \& Turk, D. C. (2017). Evidenced-based guidelines on the treatment of fibromyalgia patients: Are they consistent and if not, why not? Have effective psychological treatments been overlooked? Journal of Pain, 18, 747-756.

Torres, X., Bailles, E., Valdes, M., Gutierrez, F., Peri, J. M., Arias, A., ... Collado, A. (2013). Personality does not distinguish people with fibromyalgia but identifies subgroups of patients. General Hospital Psychiatry, 35, 640-648.

Van Houdenhove, B., Luyten, P., \& Egle, U. T. (2009). Stress as a key concept in chronic widespread pain and fatigue disorders. Journal of Musculoskeletal Pain, 17, 390-399.

Van Middendorp, H., Kool, M. B., van Beugen, S., Denollet, J., Lumley, M. A., \& Geenen, R. (2016). Prevalence and relevance of Type D personality in fibromyalgia. General Hospital Psychiatry, 39, 66-72.

Vendrig, A., Derksen, J., \& Mey, H. (2000). MMPI-2 personality psychopathology five (PSY-5) and prediction of treatment outcome for patients with chronic back pain. Journal of Personality Assessment, 74, 423-438. 